\title{
Assessment of heavy metals content and consumer health risk to Siganus fuscescens (Houttuyn, 1782) from Quang Binh province
}

\author{
Thiep V. Vo ${ }^{1,2 *}$, Yen T. $\operatorname{Tran}^{1}$, \& Anh V. Hoang ${ }^{1}$ \\ ${ }^{1}$ Faculty of Agriculture, Forestry, and Fisheries, Quang Binh University, Quang Binh, Vietnam \\ ${ }^{2}$ Institute Biology, Pedagogical University of Cracow, Kraków, Poland
}

ARTICLE INFO
Research Paper
Received: June 02, 2020
Revised: July 30,2020
Accepted: September 28, 2020
Keywords
Estimated daily intake (EDI)
Heavy metal
Siganus fuscescens
Target hazard quotients (THQ)

\section{${ }^{*}$ Corresponding author}

Vo Van Thiep

Email: vovanthiepqbu@gmail.com

\begin{abstract}
Siganus fuscescens Houttuyn, 1782 is one of the common fish species in Quang Binh province and consumers are favored by its high nutritional value. However, the consumption of Siganus fuscescens may pose potential risks to human health since they can accumulate significant amounts of heavy metals in their tissues. From July to October 2019, a total of 50 individuals of Siganus fuscescens were randomly collected through fishermen at local markets in Quang Binh province. Liver, gills, and muscles were dissected and analyzed for cadmium, lead, copper, zinc, and iron contents by the flame atomic absorption spectrometer, and the cold vapor atomic absorption spectrometer for mercury content. The metal content in all tested samples was lower than the threshold limit value by the Vietnamese Ministry of Health $(\mathrm{MoH})$. The risk to human health by the intake of metal contaminated Siganus fuscescens was evaluated by estimated daily intake (EDI), target hazard quotient (THQ), and hazard index (HI). All of the EDI values were below the provisional tolerable daily intake (PTDI) set by the $\mathrm{MoH}$, and all of THQ and HI values for male and female consumers did not exceed 1 , indicating that there was no potential human health risk in consuming Siganus fuscescens from coastal areas of Quang Binh province.
\end{abstract}

Cited as: Vo, T. V., Tran, Y. T., \& Hoang, A. V. (2020). Assessment of heavy metals content and consumer health risk to Siganus fuscescens (Houttuyn, 1782) from Quang Binh province. The Journal of Agriculture and Development 19(5), 46-54. 


\title{
Đánh giá hàm lượng kim loại nặng và rủi ro sức khỏe cho người tiêu thụ cá Dìa tro (Siganus fuscescens Houttuyn, 1782) ở tỉnh Quảng Bình
}

\author{
Võ Văn Thiệp ${ }^{1,2 *}$, Trần Thị Yên ${ }^{1}$ \& Hoàng Anh Vũ ${ }^{1}$ \\ ${ }^{1}$ Khoa Nông - Lâm - Ngư, Trường Đại Học Quảng Bình, Quảng Bình \\ ${ }^{2}$ Viện Sinh Học, Trường Đại Học Sư Phạm Cracow, Kraków, Ba Lan
}

\section{THÔNG TIN BÀI BÁO}

Bài báo khoa học

Ngày nhận: 02/06/2020

Ngày chỉnh sửa: $30 / 07 / 2020$

Ngày chấp nhận: 28/09/2020

Tù̀ khóa

Cá Dìa tro

Kim loại nặng

Thương số nguy hại

Ước tính lượng tiêu thụ hàng ngày

* Tác giả liên hệ

Võ Văn Thiệp

Email: vovanthiepqbu@gmail.com

\section{TÓM TẮT}

Cá Dìa tro là một trong những loài cá phổ biến ở ven biển tỉnh Quảng Bình và được người dân ưu chuộng vì giá trị dinh dưỡng cao. Tuy nhiên, việc tiêu thụ chúng có thể gây ra những rủi ro tiềm ẩn cho sức khỏe vì chúng có thể tích lũy đáng kể các kim loại nặng trong các mô. Từ tháng 7 đến tháng 10 năm 2019, tổng cộng 50 cá thể cá Dìa tro đã được thu thập ngẫu nhiên thông qua các ngư dân và tại các chợ cá địa phương ở tỉnh Quảng Bình. Gan, mang và cơ đã được mổ xẻ và phân tích hàm lượng cadimi, chì, đồng, kẽm và sắt bằng phương pháp quang phổ hấp thụ nguyên tử ngọn lửa và phương pháp quang phổ hấp thụ nguyên tử hóa hơi lạnh áp dụng cho xác định hàm lượng thủy ngân, tại Viện Sinh học, trường Đại học Sư phạm Kracow, Ba Lan. Hàm lượng kim loại ở trong các mẫu nghiên cứu đều nhỏ hơn giới hạn quy định của Bộ Y tế Việt Nam. Nguy cơ rủi ro bị nhiễm các kim loại nặng đối với người tiêu thụ cá Dìa tro đã được đánh giá bằng ước tính lượng kim loại tiêu thụ hàng ngày (EDI), chỉ số nguy hại (THQ) và chỉ số nguy hiểm (HI). Tất cả các giá trị EDI đều dưới ngưỡng lượng ăn vào hàng ngày có thể chấp nhận được (PTDI) quy định bởi Bộ Y tế, đồng thời tất cả các giá trị $\mathrm{THQ}$ và $\mathrm{HI}$ ở nam và nữ giới đều không vượt quá 1 . Kết quả cho thấy không có nguy cơ rủi ro đến sức khỏe khi tiêu thụ cá Dìa tro tại ven biển tỉnh Quảng Bình.

\section{1. Đặt Vấn Đề}

Quá trình đô thị hóa, công nghiệp hóa ngày càng phát triển, cùng với việc gia tăng dân số dẫn đến vấn đề ô nhiễm ngày càng tăng do lượng lớn chất thải thải ra môi trường (Naser, 2013). Một ví dụ điển hình, trong năm 2018, chỉ tính riêng lượng rác thải sinh hoạt phát sinh trên địa bàn tỉnh Quảng Bình khoảng 466 tấn/ngày, trong đó tỷ lệ thu gom, xử lý rác thải sinh hoạt bình quân chung cả tỉnh là 77.4\% (QBPPC, 2019). Theo Akcil \& ctv. (2015), các chất thải từ hoạt động nhân tạo của con người thường chứa một lượng lớn các kim loại nặng. Một khi phát thải ra môi trường, chúng theo các dòng chảy đổ vào sông và biển, đe dọa trực tiếp hoặc gián tiếp đến hệ sinh thái dưới nước do độc tính, cùng sự tồn tại lâu dài, đồng thời chúng có xu hướng tích tụ và phóng đại sinh học trong các chuỗi thức ăn (Kumar \& ctv., 2012; Rahman \& ctv., 2014).

Ở môi trường dưới nước, cá thường có vị trí cao trong các chuỗi thức ăn nên chúng có xu hướng tích lũy lớn các chất ô nhiễm (Jiang \& ctv., 2014). Do đó, bên cạnh cung cấp các chất dinh dưỡng quan trọng thì cá cũng là một mối nguy cơ tiềm ẩn mang các kim loại nặng vào cơ thể người tiêu thụ. Chính vì vậy, không quá ngạc nhiên khi trên thế giới có nhiều công trình tập trung đánh giá hàm lượng kim loại nặng và ước tính rủi ro đáng có khi tiêu thụ cá (Delgado-Alvarez \& ctv., 2017; Ali \& Khan, 2018; Solgi \& Beigzadeh-Shahraki; 2019). 
Cá Dìa tro (Siganus fuscescens Houttuyn, 1782) là một trong những loài cá biển có thịt thơm ngon, giàu dinh dưỡng và hàm lượng Omega 3 cao, nên được người dân ưu chuộng và tiêu thụ nhiều. Trên thế giới, chúng phân bố phần lớn ở Tây Thái Bình Dương, như miền Nam Hàn Quốc, Nhật Bản, Trung Quốc, Malaysia, Sigapore, Thái Lan, Indonesia, Philippines, Úc... (Froese \& Pauly, 2019). Tại Việt Nam, chúng được ghi nhận phổ biến ở các vùng nước nông, ven biển, cửa sông của các tỉnh Miền trung (MARD, 2015; Bien \& Vo, 2017; Nguyen \& ctv., 2017).

Xét thấy các số liệu còn hạn chế tại Việt Nam, các tác giả phần lớn tập trung vào lớp hai mảnh vỏ (Nguyen \& ctv., 2014; Nguyen, 2016), một số loài cá nuôi (Nguyen, 2017), trong khi đó chưa tìm thấy công bố nào liên quan đến hàm lượng kim loại nặng trong cá Dìa tro và đánh giá rủi ro tiềm ẩn khi tiêu thụ loài này. Do đó, mục đích của nghiên cứu này là đánh giá hàm lượng một số kim loại nặng (cadimi $-\mathrm{Cd}$, chì $-\mathrm{Pb}$, đồng $-\mathrm{Cu}$, kẽm - Zn, sắt - Fe, thủy ngân - Hg) trong cá Dìa tro từ vùng ven biển tỉnh Quảng Bình; đồng thời ước tính các nguy cơ tiềm ẩn đến sức khỏe con người thông qua tiêu thụ loài cá này. Nghiên cứu cung cấp một cái nhìn tổng quan về tình trạng tích lũy kim loại nặng ở cá Dìa tro, tạo cơ sở cho các cơ quan quản lý thực hiện giám sát ô nhiễm môi trường và thực hiện các biện pháp hiệu quả để giảm rủi ro sức khỏe tiềm ẩn cho người tiêu thụ.

\section{Vật Liệu và Phương Pháp Nghiên Cứu}

\subsection{Thu mẫu}

Các mẫu cá Dìa tro được thu thập ngẫu nhiên trực tiếp từ ngư dân và các chợ cá tại 5 địa điểm trên toàn tỉnh Quảng Bình (S1: xã Cảnh Dương, huyện Quảng Trạch; S2: Phường Quảng Phúc, Thị xã Ba Đồn; S3: xã Đức Trạch và S4: xã Nhân Trạch, huyện Bố Trạch; và S5: cảng cá Nhật Lệ, thành phố Đồng Hới) từ tháng 7 đến tháng 10 năm 2019 (Hình 1), các số liệu chi tiết về mẫu cá được trình bày ở Bảng 1 . Gan, mang, và cơ ở phần lưng đã được thu thập, đặt trong túi nilon có dán nhãn và được bảo quản ở nhiệt độ -18 đến $-22^{\circ} \mathrm{C}$ tại phòng thực hành trường Đại học Quảng Bình, sau đó các mẫu được chuyển đến phòng phân tích kim loại, Viện Sinh học, trường Đại học Sư phạm Kracow, Ba Lan. Trong quá trình vận chuyển bằng đường hàng không, các mẫu được bảo quản trong thùng đá ở nhiệt độ $-4^{\circ} \mathrm{C}$. Tất cả các quy trình lấy mẫu được thực hiện theo các hướng dẫn được Quốc tế công nhận (UNEP, 1991).

\subsection{Xác định hàm lượng kim loại}

Để xác định nồng độ của $\mathrm{Cd}, \mathrm{Pb}, \mathrm{Cu}, \mathrm{Zn}$ và Fe, các mẫu sau khi được rã đông, cân mỗi mẫu xấp xỉ $2 \mathrm{~g}$ trọng lượng ướt (cân có độ chính xác đến $0,0001 \mathrm{~g}$, loại cân Metler AE240), rồi đem sấy khô ở nhiệt độ $60 \mathrm{oC}$ cho đến khi đạt trọng lượng khô không đổi (với máy sấy SUP-100W, WAMED). Tiếp đến các mẫu đã sấy khô được khoáng hóa nóng với axit nitric $(65 \%$, Baker Analyzed, JT Baker, USA) trong hệ thống khoáng hóa Velp Scientifica DK20. Các dung dịch khoáng hóa được pha loãng tới $10 \mathrm{~mL}$ với nước siêu tinh khiết $\left(18,2 \mathrm{M} \Omega \mathrm{cm}\right.$ at $25^{\circ} \mathrm{C}$, Direct-Q 3, MerckMillipore, Germany) và được phân tích bằng máy quang phổ hấp thụ nguyên tử ngọn lửa (loại máy AAnalyst 200, PerkinElmer, USA). Các kết quả ban đầu thu được hiển thị với đơn vị $\mu \mathrm{g} / \mathrm{g}$ trọng lượng khô (d.w) được tính toán và chuyển sang trọng lượng ướt (w.w) dựa trên phần trăm độ ẩm $(25 \%)$.

Hàm lượng $\mathrm{Hg}$ được đo bằng máy quang phổ hấp thụ nguyên tử hơi lạnh (loại máy MA-2, NIC, Japan) trong khoảng 100 mg mẫu tươi, kết quả cuối cùng được trình bày bằng $\mu \mathrm{g} / \mathrm{g}$ w.w.

Tất cả các phân tích đều được lặp lại hai lần, giá trị trung bình của hai lần được xem là kết quả cuối cùng. Nếu độ lệch chuẩn tương đối (RSD) giữa các lần lặp lại cao hơn $15 \%$, thì phân tích được kiểm tra lại. Cứ mười mẫu, các giải pháp kiểm soát chất lượng và tăng đột biến với nồng độ kim loại được kiểm tra lại một lần với mẫu chuẩn. Tất cả các độ thu hồi (Recovery) dao động từ 90 dến $110 \%$ cho mỗi kim loại.

\section{3. Đánh giá rủi ro sức khỏe}

2.3.1. Ước tính lượng kim loại tiêu thụ hàng ngày (Estimated daily intake - EDI)

EDI của mỗi kim loại nặng tính theo công thức sau:

$$
\mathrm{EDI}=\frac{\mathrm{CM} \times \mathrm{CONS}}{\mathrm{BW}}
$$

Trong đó: EDI là lượng tiêu thụ kim loại ước tính hàng ngày (g/ngày); CM là hàm lượng kim loại trong cơ cá $(\mu \mathrm{g} / \mathrm{g}$ w.w); CONS là tî̉ lệ tiêu thụ cá hàng này, theo Ojamaa (2018) lượng tiêu thụ cá trung bình ở khu vực Miền trung là 45,21 
Bảng 1. Các giá trị trung bình, độ lệch chuẩn, nhỏ nhất và lớn nhất của cá Dìa tro tại Quảng Bình

\begin{tabular}{clcccc}
\hline & & Trung bình & Độ lệch chuẩn & Giá trị nhỏ nhất & Giá trị lớn nhất \\
\hline S1 & Trọng lượng $(\mathrm{g})$ & 97,840 & 34,484 & 45,600 & 142,000 \\
$(\mathrm{n}=10)$ & Chiều dài $(\mathrm{cm})$ & 19,822 & 2,325 & 16,238 & 22,808 \\
S2 & Trọng lượng $(\mathrm{g})$ & 101,510 & 47,563 & 39,500 & 172,000 \\
$(\mathrm{n}=10)$ & Chiều dài $(\mathrm{cm})$ & 20,217 & 3,044 & 16,248 & 24,728 \\
S3 & Trọng lượng $(\mathrm{g})$ & 77,590 & 35,420 & 32,500 & 142,300 \\
$(\mathrm{n}=10)$ & Chiều dài $(\mathrm{cm})$ & 18,686 & 2,267 & 15,800 & 22,827 \\
S4 & Trọng lượng $(\mathrm{g})$ & 83,410 & 21,762 & 57,800 & 121,200 \\
$(\mathrm{n}=10)$ & Chiều dài $(\mathrm{cm})$ & 20,113 & 1,354 & 18,419 & 22,477 \\
S5 & Trọng lượng $(\mathrm{g})$ & 107,200 & 18,577 & 75,600 & 132,500 \\
$(\mathrm{n}=10)$ & Chiều dài $(\mathrm{cm})$ & 20,624 & 1,488 & 18,700 & 23,465 \\
\hline
\end{tabular}

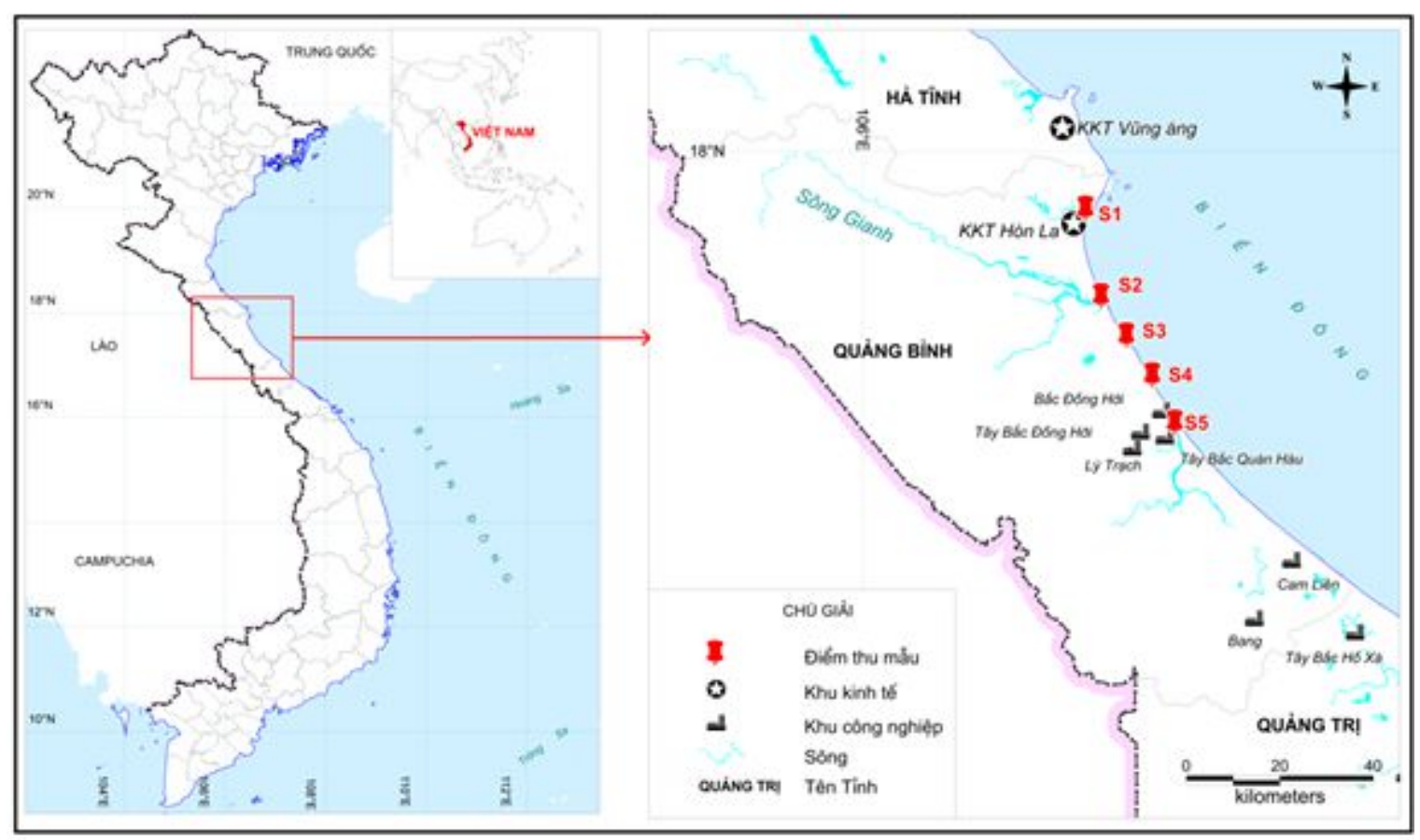

Hình 1. Vị trí thu mẫu.

g/ngày; BW là trọng lượng trung bình của người trưởng thành $(58,4 \mathrm{~kg}$ đối với nam và $50,8 \mathrm{~kg}$ đối với nữ (Tran \& ctv., 2019).

\subsection{2. Ước tính chỉ số nguy hại (Target hazard quo- tients - THQ)}

THQ đã được sử dụng để ước tính nguy cơ không gây ung thư của các chất ô nhiễm tích lũy trong các mô của cá. Đó là tî lệ của EDI và tỉ lệ tham chiếu (reference dose (RfD)) được đặt ra bởi USEPA (2019). Theo đó, RfD của $\mathrm{Cd}, \mathrm{Pb}$, $\mathrm{Cu}, \mathrm{Zn}, \mathrm{Fe}$ và $\mathrm{Hg}$ lần lượt là 0,$001 ; 0,004 ; 0,04$;
0,$3 ; 0,6$ và $0,0003 \mu \mathrm{g} / \mathrm{g} /$ ngày.

$$
\mathrm{THQ}=\frac{\mathrm{EDI}}{\operatorname{den}} \times 10^{-3}
$$

Tổng THQ (hay còn gọi là chỉ số nguy hiêm $\mathrm{HI})$ được tính bằng tổng của từng THQ kim loại riêng lẻ cho từng loài cá. Nếu $\mathrm{HI}<1$ có nghĩa là người tiêu thụ được coi là an toàn (USEPA, 2019).

\subsection{Phân tích thống kê}

Thử nghiệm "Shapiro - Wilk test" được dùng để kiểm tra sự phân bố của hàm lượng kim loại 
Bảng 2. Giá trị trung bình, trung vị, tối thiểu, tối đa và độ lệch chuẩn của kim loại trong cá Dìa tro ở tỉnh Quảng Bình

\begin{tabular}{cccccccc}
\hline & \multicolumn{6}{c}{ Kim loại $(\mu \mathrm{g} / \mathrm{g}$ w.w $)$} \\
\cline { 3 - 8 } & & $\mathrm{Cd}$ & $\mathrm{Pb}$ & $\mathrm{Cu}$ & $\mathrm{Zn}$ & $\mathrm{Fe}$ & $\mathrm{Hg}$ \\
\hline \multirow{4}{*}{ Gan } & Trung bình & 0,022 & 0,020 & 0,456 & 0,440 & 2,479 & 0,114 \\
& Trung vị & 0,018 & 0,011 & 0,370 & 0,407 & 2,317 & 0,071 \\
& Nhỏ nhất & 0,009 & 0,003 & 0,161 & 0,096 & 1,301 & 0,032 \\
& Lớn nhất & 0,067 & 0,087 & 0,923 & 0,912 & 5,071 & 0,555 \\
& Độlệch chuẩn & 0,013 & 0,023 & 0,214 & 0,193 & 0,863 & 0,116 \\
\hline \multirow{4}{*}{ Mang } & Trung bình & 0,017 & 0,015 & 0,251 & 0,298 & 2,204 & 0,033 \\
& Trung vị & 0,016 & 0,014 & 0,164 & 0,295 & 1,915 & 0,032 \\
& Nhỏ nhất & 0,007 & 0,002 & 0,008 & 0,132 & 0,998 & 0,018 \\
& Lớn nhất & 0,026 & 0,040 & 0,699 & 0,608 & 3,988 & 0,061 \\
& Độlệch chuẩn & 0,006 & 0,011 & 0,189 & 0,103 & 0,890 & 0,010 \\
\hline \multirow{4}{*}{ Cơn } & Trung bình & 0,015 & 0,025 & 0,133 & 0,245 & 1,347 & 0,080 \\
& Trung vị & 0,014 & 0,010 & 0,095 & 0,227 & 1,027 & 0,079 \\
& Nhỏ nhất & 0,005 & 0,001 & 0,008 & 0,093 & 0,835 & 0,036 \\
& Lớn nhất & 0,026 & 0,338 & 0,401 & 0,483 & 3,408 & 0,143 \\
& Độ lệch chuẩn & 0,005 & 0,054 & 0,097 & 0,090 & 0,630 & 0,028 \\
\hline
\end{tabular}

trong các mẫu. Do các mẫu có sự phân bố không chuẩn nên "Kruskal-Wallis test" được thực hiện để xác định khác biệt đáng kể sự tích lũy kim loại trong cá mô cá. Tất cả các tính toán thống kê được thực hiện với phần mềm thống kê Statistica 13.3 (StatSoft, Ba Lan). Kết quả thống kê có ý nghĩa khi giá trị p bằng hoặc nhỏ hơn 0,05 .

\section{Kết Quả và Thảo Luận}

\subsection{Hàm lượng kim loại nặng trong cá}

Kết quả phép đo sinh trắc của cá Dìa tro (chiều dài và cân nặng) được thể hiện ở Bảng 1 . Trung bình chiều và trọng lượng lớn nhất lần lượt là $20,624 \mathrm{~cm}$ và $107,2 \mathrm{~g}$ thu được ở vùng $\mathrm{S} 5$, trong khi đó chiều dài và trọng lượng trung bình nhỏ nhất là $18,686 \mathrm{~cm}$ và $77,590 \mathrm{~g}$ thu được tại vùng S3. Kết quả phân tích thống kê cũng cho thấy không có sự khác biệt đáng kể về chiều dài và trọng lượng của cá Dìa tro ở 5 vùng nghiên cứu. Mối tương quan giữa chiều dài và trọng lượng là tương quan thuận $\left(\mathrm{r}^{2}=0,92\right)$ và theo phương trình sau:

$$
\mathrm{L}=5,7468 \times \mathrm{W}^{0,2758}
$$

Trong đó: L - chiều dài $(\mathrm{cm}), \mathrm{W}$ - trọng lượng (g). Giá trị trung bình, trung vị, nồng độ nhỏ nhất, lớn nhất và độ lệch chuẩn của các kim loại trong gan, mang và cơ của cá Dìa tro được tóm tắt trong Bảng 2. Theo đó, sự tích lũy kim loại ở trong gan, mang và cơ lần lượt theo thứ tự giảm dần như sau: $\mathrm{Fe}>\mathrm{Cu}>\mathrm{Zn}>\mathrm{Hg}>\mathrm{Cd}$ $>\mathrm{Pb} ; \mathrm{Fe}>\mathrm{Zn}>\mathrm{Cu}>\mathrm{Hg}>\mathrm{Cd}>\mathrm{Pb} ; \mathrm{Fe}>$ $\mathrm{Zn}>\mathrm{Cu}>\mathrm{Hg}>\mathrm{Pb}>\mathrm{Cd}$. Kết quả phân tích cho thấy sự tích lũy các kim loại ở trong cơ là thấp nhất, trong khi ở gan và mang lại cao hơn. Với phép kiểm tra "Kruskal-Wallis ANOVA" và phép so sánh thứ hạng giá trị trung bình cho các kim loại giữa các cơ quan cho thấy có sự khác biệt đáng kể về nồng độ kim loại giữa chúng, được thể hiện rõ trong Hình 2. Sự tích lũy của các kim loại cao ở trong gan vì gan đóng vai trò quan trọng trong quá trình trao đổi chất (Zhao \& ctv., 2012). Trong khi mang là nơi trao đổi trực tiếp của các ion kim loại ở trong nước với cơ thể của cá, do đó dấu vết kim loại ở trong mang thường cao hơn trong cơ (Qadir \& Malik, 2011). Đây cũng là lí do mang cá thường được xem xét như là một tiêu chí để phản ánh chất lượng môi trường nước, nơi chúng sống (El-Moselhy \& ctv., 2014).

Kết quả của nghiên cứu này tương tự với báo cáo của Liu \& ctv. (2015) tại bờ biển phía nam của Trung Quốc, đó là hàm lượng kim loại nặng có xu hướng tập trung cao ở gan, mang hơn là ở trong cơ. Tuy nhiên, Liu \& ctv. (2015) đã cho thấy sự tích lũy $\mathrm{Cd}, \mathrm{Pb}, \mathrm{Zn}$ và $\mathrm{Cu}$ ở trong gan, mang và cơ cao hơn trong báo cáo này. Trước đó, tại vùng biển của Indonesia, Bramandito \& ctv. (2018) đã trình bày nồng độ $\mathrm{Cd}(0,27 \mathrm{\mu g} / \mathrm{g}$ w.w) và $\mathrm{Cu}(3,92 \mu \mathrm{g} / \mathrm{g}$ w.w) ở trong cơ cá Dìa cao hơn tại vùng ven biển Quảng Bình. Trong 

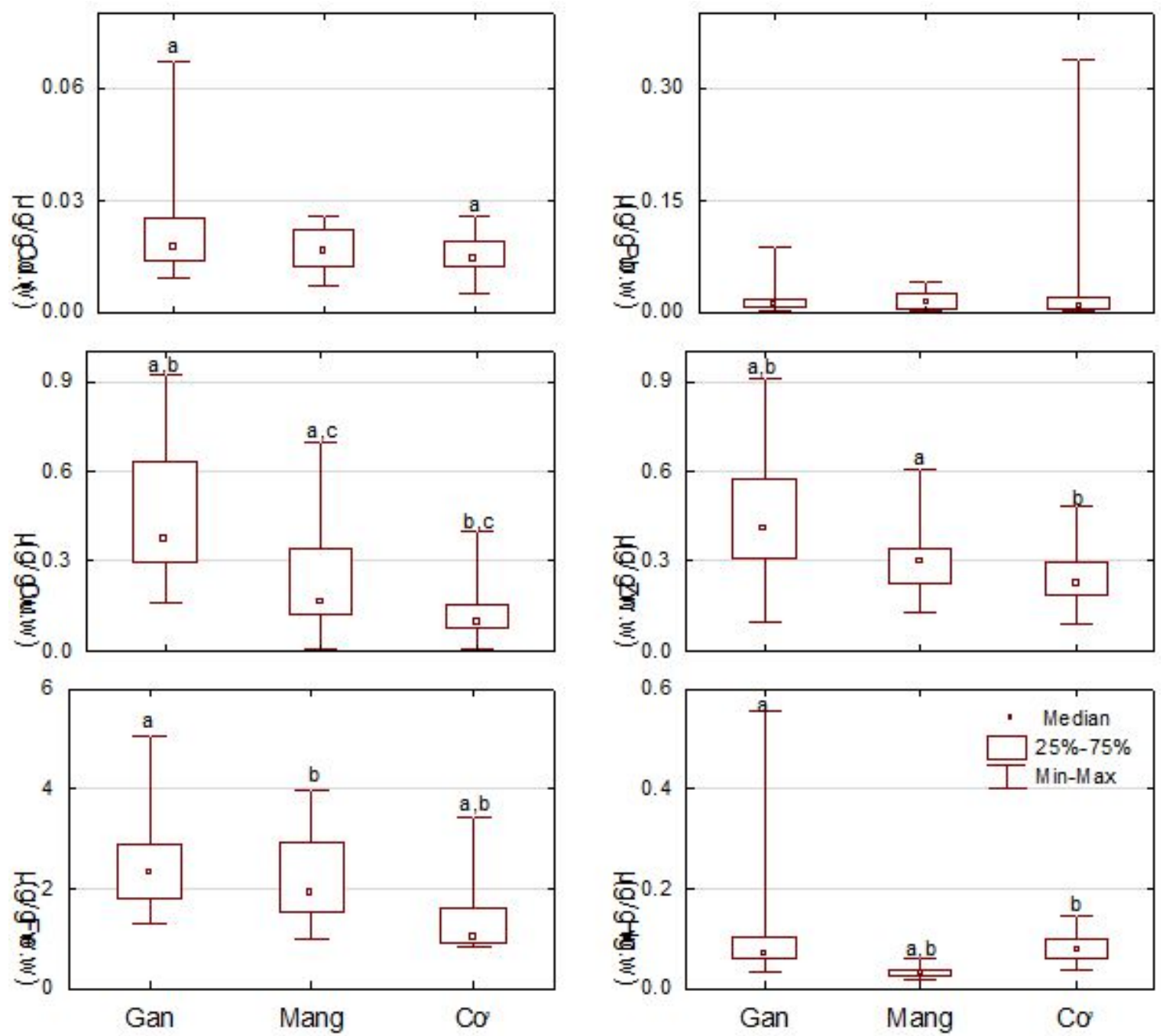

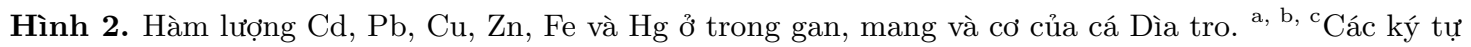
giống nhau thể hiện sự khác biệt có ý nghĩa thống kê, $P<0,05$.

báo cáo về hàm lượng kim loại nặng của 29 loài cá ven biển Trung Quốc, Zhang \& Wang (2012) đã cho thấy nồng độ của $\mathrm{Pb}(0,068 \mu \mathrm{g} / \mathrm{g}$ w.w) và Fe $(6,445 \mu \mathrm{g} / \mathrm{g}$ w.w $)$ ở trong cơ cá Dìa tro là cao hơn, trong khi nồng độ $\mathrm{Cd}(0,135 \mu \mathrm{g} / \mathrm{g} \mathrm{w} . \mathrm{w})$ và Zn $(0,273 \mu \mathrm{g} / \mathrm{g}$ w.w) lại xấp xỉ, còn hàm lượng $\mathrm{Cu}(0,02 \mu \mathrm{g} / \mathrm{g}$ w.w $)$ thì thấp hơn so với báo cáo này. Bên cạnh đó, Pan \& ctv. (2014) đã trình bày hàm lượng $\mathrm{Hg}$ ở trong cơ là khá thấp $(0,005 \mathrm{\mu g} / \mathrm{g}$ w.w), trong khi Onsanit \& ctv. (2012) và Chen \& ctv. (2018) lại có trình bày cao hơn $(0,03$ và 0,018 $\mu \mathrm{g} / \mathrm{g}$ w.w) so với nghiên cứu này. Cùng một loài cá nhưng ở các địa điểm khác nhau thì sự tích lũy của kim loại trong cơ thể là khác nhau, vì sự tích lũy này chịu ảnh hưởng bởi các yếu sinh học và phi sinh học bao gồm môi trường sống của cá, nhiệt độ nước, giá trị $\mathrm{pH}$, nồng độ oxy hòa tan, dạng hóa học của các kim loại trong nước, ngoài ra các yếu tố như tuổi, giới tính, trọng lượng cơ thể cũng ảnh hưởng đến sự tích lũy các kim loại (Putri \& ctv., 2017).

So với Quy chuẩn kỹ thuật Quốc gia đối với giới hạn ô nhiễm kim loại nặng trong thực phẩm của Bộ Y tế (MoH, 2011), mặc dù giá trị trung bình của tất cả các mẫu được xét nghiệm đều dưới ngưỡng cho phép, nhưng vẫn có một số mẫu vượt qua quy chuẩn ( $\mathrm{Cd}$ và $\mathrm{Hg}$ ở trong gan, $\mathrm{Pb}$ ở trong cơ), do đó để xác định mức độ an toàn cho người tiêu thụ thì cần phải xem xét đến lượng tiêu thụ hàng ngày đối với loài cá đó. 
Bảng 3. Giá trị ước tính lượng tiêu thụ hàng ngày (EDI), chỉ số nguy hại (THQ) và tổng chỉ số nguy hại $(\mathrm{HI})$ của các kim loại đối với việc tiêu thụ cá Dìa tro

\begin{tabular}{ccccccccc}
\hline & & $\mathrm{Cd}$ & $\mathrm{Pb}$ & $\mathrm{Cu}$ & $\mathrm{Zn}$ & $\mathrm{Fe}$ & $\mathrm{Hg}$ & $\mathrm{HI}$ \\
\hline \multirow{2}{*}{ EDI } & Nam & 0,012 & 0,019 & 0,103 & 0,190 & 1,043 & 0,062 & \\
& Nữ & 0,013 & 0,022 & 0,118 & 0,218 & 1,199 & 0,071 & \\
\hline \multirow{2}{*}{ THQ } & Nam & 0,012 & 0,005 & 0,003 & 0,001 & 0,002 & 0,206 & 0,228 \\
& Nũ & 0,013 & 0,006 & 0,003 & 0,001 & 0,002 & 0,237 & 0,262 \\
\hline
\end{tabular}

\section{2. Đánh giá rủi ro sức khỏe đối với người tiêu thụ cá}

Cơ cá là phần chính trong việc tiêu thụ, do đó hàm lượng kim loại nặng trong cơ được xem xét để đánh giá rủi ro ảnh hưởng đến sức khỏe của người tiêu thụ. Giá trị EDI, THQ và $\mathrm{HI}$ đối với việc tiêu thụ cá Dìa tro ở nam giới và nữ giới tại Quảng Bình được trình bày trong Bảng 3 .

Giá trị EDI cao nhất được tìm thấy đối với $\mathrm{Fe}$ ở nữ giới $(1,199$ p/g/ngày), trong khi giá trị thấp nhất được phát hiện đối với $\mathrm{Cd}$ ở nam giới $(0,012$ $\mu / g / n g a ̀ y)$. Giá trị THQ ở nam và nữ đều theo thứ tự giảm dần như sau: $\mathrm{Hg}>\mathrm{Cd}>\mathrm{Pb}>\mathrm{Cu}$ $>\mathrm{Fe}>\mathrm{Zn}$. Trong đó các giá trị THQ ở nữ giới đều cao hơn so với nam giới.

Tổ chức Lương thực và Nông nghiệp Liên Hiệp Quốc, tổ chức Y tế Thế giới (FAO/WHO, 1982), và Bộ Y tế Việt Nam $(\mathrm{MoH}, 2011)$ dã thiết lập lượng ăn vào hàng ngày có thể chấp nhận được tạm thời (Provisional Tolerable Daily Intake PTDI) đối với $\mathrm{Cd}, \mathrm{Pb}, \mathrm{Cu}, \mathrm{Zn}, \mathrm{Fe}$ và $\mathrm{Hg}$ lần lượt là 1,$00 ; 3,571 ; 500 ; 300-1000 ; 800$ và 0,714 $\mathrm{\mu g} / \mathrm{kg}$ trọng lượng cơ thể/ngày. Trong báo cáo này, tất cả các giá trị EDI của kim loại ở người tiêu thụ nam và nữ giới đều nằm dưới ngưỡng PTDI. Thêm vào đó, các giá trị THQ của từng kim loại cũng như giá trị HI của tất cả các kim loại đều nhỏ hơn 1 , điều này cho thấy không có bất kỳ rủi ro nào ảnh hưởng đến sức khỏe của người tiêu thụ loài cá này tại ven biển Quảng Bình. Trước đó, Vo \& ctv. (2019) và Vo \& Huynh (2019) cũng đã có những đánh giá liên quan đến rủi ro tiềm ẩn khi tiêu thụ các loài cá Đối mục, cá Móm gai dài và cá Đục bạc ở vùng ven biền Quảng Bình, nhóm tác giả cũng cho thấy giá trị EDI và THQ đều ở dưới ngưỡng an toàn.

Mặc dù chỉ số THQ cho thấy không có bất kỳ rủi ro nào nhưng nó mới chỉ thực hiện trên 6 kim loại, và trong khoảng thời gian ngắn. Do đó việc đánh giá, theo dõi mức độ ô nhiễm kim loại trong cá phải được thực hiện thận trọng và thường xuyên, qua đó phát hiện được bất kỳ những thay đổi có thể trở thành mối nguy hiểm cho người tiêu thụ. Hơn nữa, cần mở rộng việc đánh giá trên nhiều đối tượng, nhiều kim loại, phạm vi lấy mẫu để đưa ra được những dự báo chính xác nhất.

\section{Kết Luận}

Nghiên cứu đã cung cấp dữ liệu cơ bản sự tích lũy của các kim loại nặng trong gan, mang và cơ của cá Dìa tro ở ven biển Quảng Bình và đánh giá các rủi ro sức khỏe tiềm ẩn liên quan đến việc tiêu thụ loài cá này cho nam và nữ giới. Tất cả các mẫu kiểm tra đều có hàm lượng kim loại nằm dưới ngưỡng của Quy chuẩn kỹ thuật Quốc gia đối với giới hạn ô nhiễm kim loại nặng trong thực phẩm của Bộ Y tế. Đồng thời giá trị EDI của các kim loại cũng không vượt quá ngưỡng PTDI. Chỉ số THQ và $\mathrm{HI}$ cho thấy không có rủi ro tiềm ẩn nào đến sức khỏe con người khi tiêu thụ loài cá này. Qua đây, nhóm tác giả cũng đề nghị cần theo dõi liên tục các kim loại nặng trong nhiều loài cá khác nhau, từ nhiều vùng, để đánh giá chính xác các rủi ro tiềm ẩn từ việc tiêu thụ với các nguồn kim loại này.

\section{Lời Cảm Ơn}

Nhóm tác giả xin chân thành cảm ơn Tiến sĩ Włodzimierz Wojtaś, Tiến sĩ Tomasz Łaciak ở Viện Sinh học, Trường Đại học Sư phạm Cracow, Ba Lan đã hỗ trợ trong việc phân tích hàm lượng các kim loại.

\section{Tài Liệu Tham Khảo (References)}

Akcil, A. C. E., Erust, C., Ozdemiroglu, S., Fonti, V., \& Beolchini, F. (2015). A review of approaches and techniques used in aquatic contaminated sediments: metal removal and stabilization by chemical and biotechnological processes. Journal of Cleaner Production 86, 24-36. 
Ali, H., \& Khan, E. (2018). Bioaccumulation of nonessential hazardous heavy metals and metalloids in freshwater fish. Risk to human health. Environmental Chemistry Letters 16(3), 903-917.

Bien, V. Q., \& Vo, V. P. (2017). A preliminary study on species composition fishes of fishesin coastal waters of Ha Tinh province. In Le, X. C. (Ed.). Proceedings of the rth National Scientific Conference on Ecology and Biological Resources (883-891). Ha Noi, Vietnam: Publishing House for Science \& Technology.

Bramandito, A., Subhan, B., Prartono, T., Anggraini, N. P., Januar, H. I., \& Madduppa H. H. (2018). Genetic diversity and population structure of Siganus fuscescens across urban reefs of Seribu Islands, Northern of Jakarta, Indonesia. Biodiversitas 19, 1993-2002.

Chen, S., Chen, Z., Wang, P., Huang, R., Huo, W., Huang, W., \& Peng J. (2018). Health risk assessment for local residents from the South China Sea based on mercury concentrations in marine fish. Bulletin of Environmental Contamination and Toxicology 101(3), 398-402.

Delgado-Alvarez, C. G., Frías-Espericueta, M. G., RuelasInzunza, J., Becerra-Álvarez, M. J., Osuna-Martínez, C. C., Aguilar-Juárez, M., \& Voltolina, D. (2017). Total mercury in muscles and liver of Mugil spp. from three coastal lagoons of NW Mexico: concentrations and risk assessment. Environmental Monitoring and Assessment 189(7), 312.

El-Moselhy, K. M., Othman, A. I., Abd El-Azem, H., \& El-Metwally, M. E. A. (2014). Bioaccumulation of heavy metals in some tissues of fish in the Red Sea, Egypt. Egyptian Journal of Basic and Applied Sciences 1(2), 97-105.

FAO/WHO (Food and Agriculture Organization/World Health Organization). (1982). Evaluation of certain food additives and contaminants. Twenty-sixth Report of the Joint FAO/WHO Expert Committee on Food Additives. Geneva, Switzerland: World Health Organization.

Froese, R., \& Pauly, D. (2019). Mottled spinefoot Siganus fuscescens (Houttuyn, 1782). Retrieved May 31, 2020, from https://www.fishbase.se/summary/Siganusfuscescens.

Jiang, D., Hu, Z., Liu, F., Zhang, R., Duo, B., Fu, J., \& Li, M. (2014). Heavy metals levels in fish from aquaculture farms and risk assessment in Lhasa, Tibetan $\mathrm{Au}-$ tonomous Region of China. Ecotoxicology 23(4), 577583.

Kumar, B., Sajwan, K. S., \& Mukherjee, D. P. (2012). Distribution of heavy metals invaluable coastal fishes from the North East Coast of India. Turkish Journal of Fisheries and Aquatic Sciences 12, 81-88.

Liu, J. L., Xu, X. R., Ding, Z. H., Peng, J. X., Jin, M. H., Wang, Y. S., Hong, Y. G., \& Yue W. Z. (2015). Heavy metals in wild marine fish from South China Sea: levels, tissue-and species-specific accumulation and potential risk to humans. Ecotoxicology 24(7-8), 15831592 .
MARD (Ministry of Agriculture and Rural Development). (2015). Summary report on aquaculture development planning of central provinces to 2020 and orientation to 2030. Ha Noi, Vietnam.

MoH (Ministry of Health of Vietnam). (2011). National technical regulation on the safety limits of heavy metals contaminants in food. QCVN 8-2:2011/BYT. Ha Noi, Vietnam.

Naser, H. A. (2013). Assessment and management of heavy metal pollution in the marine environment of the Arabian Gulf: a review. Marine Pollution Bulletin 72(1), 6-13.

Nguyen, M. T. (2016). Determining and evaluating maganese and zinc content in oysters Crassostrea rivularis (Gould, 1861) in Gianh river, Ba Don town, Quang Binh. The DUEd Journal of Science and Education 20(3), 54-60.

Nguyen, M. T. (2017). Determination the manganese and zinc content in Red tilapia at Bac Nghia ward, Dong Hoi city, Quang Binh province. Scientific Journal of Hanoi Metropolitan University 3(39), 42-45.

Nguyen, V. K., Tran, D. V., \& Le H. Y. N. (2014). Heavy metal content $(\mathrm{Hg}, \mathrm{Cd}, \mathrm{Pb}, \mathrm{Cr})$ in bivalve shellfish in some estuaries in the central region, Vietnam. Vietnam Journal of Marine Science and Technology 4, 385-392.

Nguyen, X. H., Nguyen, T. N., \& Ta., P. D. (2017). Diversity of fish species in the coastal area of Gianh estuary, Quang Binh province. In Le, X.C. (Ed). Proceedings

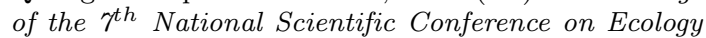
and Biological Resources (206-213). Ha Noi, Vietnam: Publishing House for Science \& Technology.

Ojamaa, P. (2018). Research for PECH Committee - Fisheries in Vietnam. Policy Department for Structural and Cohesion Policies Directorate-General for Internal Policies $P E$ 629.175. Retrieved May 31, 2020, from http://www.europarl.europa.eu/RegData/etudes/IDA N/2018/629175/IPOL_IDA(2018)629175_EN.pdf.

Onsanit, S., Chen, M., Ke, C., \& Wang, W. X. (2012). Mercury and stable isotope signatures in marine caged fish and fish feeds. Journal Hazard Materials 203/204, 13-21.

Pan, K., Chan, H., Tam, Y. K., \& Wang W. X. (2014). Low mercury levels in marine fish from estuarine and coastal environments in southern China. Environmental Pollution 185, 250-257.

Putri, A. K., Barokah, G. R., \& Andarwulan N. (2017). Human health risk asessment of heavy metals bioaccumulation in fish and mussels from Jakarta bay. Squalen Bulletin of Marine and Fisheries Postharvest and Biotechnology 12(2), 75-83.

Qadir, A., \& Malik, R. N. (2011). Heavy metals in eight edible fish species from two polluted tributaries (Aik and Palkhu) of the River Chenab, Pakistan. Biological Trace Element Research 143, 1524-1540. 
QBPPC (Quang Binh Provincial People's Committee). (2019). Socio-economic situation in 2019. Report No. 267/BC-UBND dated November 28, 2019. Quang Binh, Vietnam.

Rahman, M. S., Saha, N., Molla, A. H., \& Al-Reza, S. M. (2014). Assessment of anthropogenic influence on heavy metals contamination in the aquatic ecosystem components: water, sediment, and fish. Soil and Sediment Contamination: An International Journal 23(4), 353-373.

Solgi, E., \& Beigzadeh-Shahraki, F. (2019). Accumulation and human health risk of heavy metals in Cultured Rainbow Trout (Oncorhynchus mykiss) form different fish farms of Eight Cities of Chaharmahal and Bakhtiari province, Iran. Thalassas: An International Journal of Marine Sciences 35(1), 305-317.

Tran, Q. C., Le, V. B., Nguyen, A. T., Vo, V. T., Nguyen, M. Q., Yang, S. H., \& Tuyen, V. D. (2019). Associated factors of hypertension in women and men in Vietnam: A cross-sectional study. International Journal of Environmental Research and Public Health 16(23), 47144728.

UNEP (United Nations Environment Programme). (1991). Sampling of selected marine organisms and sample preparation for the analysis of chlorinated hydrocarbons. Reference Methods for Marine Pollution Studies. 12, Rev. 2. UNEP, Nairobi.
USEPA (United States Environmental Protection Agency). (2019). Regional screening levels (RSLs) - Generic Tables. Washington, DC. Retrieved May 31, 2020, from https://semspub.epa.gov/work/HQ/199660.pdf.

Vo, V. T, Huynh, N. T., \& Le, T. T. P. (2019). Determination of heavy metals levels ( $\mathrm{Fe}, \mathrm{Cd}, \mathrm{Pb}, \mathrm{Zn}$ and $\mathrm{Cu}$ ) in Mugil cephalus from Quang Binh, Vietnam. Journal of Biology 41(2se1\&2se2), 451-459.

Vo, V. T., \& Huynh, N. T. (2019). Esyimination of Target hazard quotient (THQ) for heavy metal by consumption of some fish species in Quang Binh. Quang Binh University Journal of Science and Technology 19(3), 22-30.

Zhang, W., \& Wang, W. X. (2012). Large-scale spatial and interspecies differences in trace elements and stable isotopes in marine wild fish from Chinese waters. Journal of Hazardous Materials 215/216, 65-74.

Zhao, S., Feng, C., Quan, W., Chen, X., Niu, J., \& Shen, Z. (2012). Role of living environments in the accumulation characteristics of heavy metals in fishes and crabs in the Yangtze River Estuary, China. Marine Pollution Bulletin 64, 1163-1171. 